Int. J. Dev. Biol. 64: 35-40 (2020)

https://doi.org/10.1387/ijdb.190171ar

\title{
Fields, patterns and information: R.L. Brahmachary's contributions during the infancy of molecular embryology
}

\author{
ANIMESH RAY*,1,2 \\ ${ }^{1}$ Riggs School of Applied Life Sciences, Keck Graduate Institute, Claremont, CA and \\ ${ }^{2}$ Division of Biology and Biological Engineering, California Institute of Technology, Pasadena, California, USA
}

\begin{abstract}
The contribution of Professor Ratan Lal Brahmachary's research during the early years of molecular embryology, its theoretical underpinnings, and its connection with those of other contemporary research efforts, are traced in this article as a part of the history of developmental biology research in India.
\end{abstract}

KEY WORDS: early embryogenesis, morphogen, pattern formation, informational molecule, Limnaea

In the early 1960s, the time was ripe for asking questions about how morphological patterns in the embryo are formed in a programmed manner. For those who had cut their teeth on physics-as young Ratan Lal Brahmachary (RLB) (1932-2018) had done in the 1940s and 50s - the influence of Erwin Schrödinger's "What is life" was a "guiding principle" (Schrödinger, 1944). In Schrödinger's words:

"...the guiding principle in every cell is embodied in a single atomic association existing only in one copy (or sometimes two)...(which) results in producing events that are paragons of orderliness....It appears that there are two 'mechanisms' by which orderly events can be produced: 'statistical mechanisms' which produce 'order from disorder' and the new one, producing 'order from order'..." (Schrödinger, 1944). DNA, the molecule of heredity, the source of 'order' or 'instruction' in living cells, turned out to be every bit the "aperiodic" molecule that Schrödinger had speculated it to be, only more elegant and beautiful. That DNA somehow encoded the information on a programmed unfurling of pattern in the embryo was clear by 1960 , seven years after the proposal of its structure. However, the existence of information transfer from DNA to mRNA to protein was barely demonstrated by 1961 (Brenner et al., 1961); genetic code was not yet deciphered (Crick, 1963); that ribosome was the site of protein synthesis, which can be regulated, was barely demonstrated (Stent and Brenner, 1961); and models of how genes might be regulated (Jacob and Monod, 1961) had just been published. During that time of great excitement in molecular biology, RLB, up to then having published a few papers on certain solutions of general relativistic field equations (Brahmachary, 1953a, 1953b, 1955a, 1955b, 1957), decided to jump into embryology (Brahmachary, R.L., 1962, 1963).

At that time, there was a simple idea about how patterns could be formed in biological systems. There was considerable evidence that the egg might not be fully symmetric, but that it is inherently asymmetric. Several embryologists had already demonstrated this by a series of elegant experiments on newt, Axolotl, and the African clawed toad. An elegant mathematical demonstration eight years earlier by Alan Turing (Turing, 1952) lent credence to the idea that without any additional hypothesis than merely the existence of two mutually opposing directional diffusions of some active substances (morphogens), for which there was firm footing at the time (Gilbert, 2000), it is possible to generate complex spatial and temporal patterns. The connection between genes as the informational molecules and morphogens as the creative determinants of 'reactive fields' had compelling attractiveness, and had previously been suggested by C.H. Waddington in the UK (Waddington, 1940), himself having been profoundly influenced by Norbert Wiener (Waddington, 1975), the founder of information theory at Massachusetts Institute of Technology (Cambridge, USA), and was tantalizingly being explored by Ed Lewis at the California Institute of Technology (Pasadena, California) in terms of the body plan of the fruit fly (Lewis, 1963). Lewis had co-opted the chemical formalism of cis-trans configuration of alleles, first introduced into genetics by J.B.S. Haldane (Haldane, 1941), to make the case that gene mutations affect the sequential expression of a morphogenetic field in the fly, and that these genes could be mapped along a linear array on the linkage groups, which reflected the spatial domains of their phenotypic action.

While it is possible that Haldane, who was resident at the Indian Statistical Institute (1956-1960), could have made an early impres-

Abbreviations used in this paper: AR, Animesh Ray; RLB, Ratan Lal Brahmachary.

*Address correspondence to: Animesh Ray. Riggs School of Applied Life Sciences, Keck Graduate Institute, 535 Watson Drive, Claremont, CA 91711, USA.
Tel: +1 858344 4744. E-mail: aray@ kgi.edu; animesh@ @ caltech.edu - iD https://orcid.org/0000-0002-0120-5820

Supplementary Material (one letter, one video) for this paper is available at: https://doi.org/10.1387/ijdb.190171ar

Submitted: 8 July, 2019 Accepted: 19 August, 2019.

ISSN: Online 1696-3547, Print 0214-6282

(C) 2020 UPV/EHU Press

Printed in Spain 
sion on RLB - Haldane strongly supported the idea that genes are directly involved in encoding developmental cues during early morphogenesis (Haldane, J.B.S, 1941), the so-called "creative" phase in which more complex patterns arise out of seemingly simpler morphogenetic fields - there is no material evidence in its support.

The revolution in molecular biology in the West at that time must have provoked RLB to seek answers to the question on how genes induce patterns in the embryo. Crucially, one needed to discover how the information from DNA could be expressed as an asymmetric morphogen gradient to lay down the programmed series of developmental changes. However, this idea was far from the minds of most embryologists at the time. For example, the first definitive studies on DNA in the eggs of African clawed toad was published in 1965, wherein the author Igor Dawid (Carnegie Institution of Washington, Baltimore, USA) concluded rather tentatively:

"Regarding the function of egg DNA, only speculations can be offered at present. The storage hypothesis appears unlikely. The large pool of soluble deoxyribose compounds in the egg, presumably mononucleotides, most probably serves such a storage function, as does the still larger pool of ribonucleotides..." (Dawid, 1965).

Meanwhile, Finamore and Crouse had demonstrated that there is a store of RNA molecules in the cytoplasm of amphibian eggs but that there was little incorporation of fresh nucleotides into these RNA fractions until fertilization began (Finamore and Crouse, 1958). Might these stored RNA molecules be the agents of informational asymmetry in the frog's eggs? In August of 1967, RLB wrote:

"The fundamental problems of molecular embryology today are the why and how of information transfer, namely the decoding of genetic message in course of development" (Brahmachary et al., 1968).

In a formal information-theoretic framework, the problem can be expressed in terms of three components: The emitter of information, the transmitter, and the receiver. RLB's thinking in these specific physical terms was evident in his 1968 publication:

"...the unfertilized egg is dormant...not because the transmitter and receiver ends of the information transfer system (i.e., mRNA and ribosome) is absent or non-functional.." (Brahmachary et al., 1968).

Metaphors are important in the progress of science, as Evelyn Fox Keller has argued persuasively (Keller, 1995), and some of these metaphors, such as Hans Spemann's "Organizer Principle" as a set of instructions to specify developmental pattern (Spemann, 1927) and Erwin Schrödinger's ideas on Maxwell's Demon as a principle that works on systems of diffusing chemicals by using "information" to decrease local entropy (Schrödinger, 1944), thus serving as the fundamental basis of biological form, were instrumental in forming the conceptual underpinnings of the early pioneers. RLB's intellect had found a natural transition from tensor fields of relativistic space-time to morphogenetic fields of diffusing organizers and informational macromolecules.

In the early 1960s embryologists were using sea urchin as a popular model for investigating invertebrate embryogenesis. There were three main reasons why RLB did not choose sea urchin. It was difficult to obtain and maintain sea urchins in Calcutta, being some distance away from the sea; sea urchins had rather difficult genetics and RLB had anticipated (personal communication to AR) that in time genetics would be needed to decipher the intricacies of information flow during embryogenesis; finally, RLB had generally wished to distinguish his work from those of researchers in the west, which meant that he was always looking for a uniquely creative angle best suited to the research climate of India, particularly of Bengal.

While his questions were the same as those asked by the pioneering researchers in the west, such as Eric Davidson (USA), Jean Brachet (Belgium), J. B. Gurdon (Cambridge, UK), and Sol Spiegelman (USA), RLB's distinguishing marks were to conscript the freshwater snail, Limnaea, to molecular embryology. Limnaea was a particularly shrewd choice, because some fifty years earlier genetic analysis had indicated that the chirality ('handedness' of coiling) of the shell is an inherited characteristic expected of a single Mendelian 'gene' (Sturtevant, 1923), anticipating an accessible genetic paradigm with this organism as a model. Importantly, the genetic analysis conducted by researchers in England (Boycott, A.E., and Diver, C., 1923) indicated, according to Sturtevant:

"... that we shall have here a model case of the Mendelian inheritance of an extremely ... fundamental" character, and a character that is impressed on the egg by the mother" (Sturtevant, 1923).

The importance of this observation for an information-theoretic view is unquestionable: what better source of the 'information generator' than the mother's genes! The timeliness of this choice is attested by the fact that Sydney Brenner in Cambridge began his famous search for a tractable genetic model for developmental biology around the same time to ultimately settle on Caenorhabditis elegans in the summer of 1963.

Already in 1962 RLB had asked the first important question with Limnaea: is there an evidence that the informational field in the early stages of embryogenesis is pre-made? If true, then one would anticipate little de novo synthesis of informational macromolecules in the early embryo, most of them having been possibly donated by the mother, pre-loaded into the egg. In response, at the information receiver end, new proteins would be synthesized in the developing embryos. Since new proteins are made from many amino acids "in one stroke", one should be able to detect (a) the presence of many free amino acids, and (b) the incorporation of fresh amino acids into proteins in the early embryos. The beguilingly simple technique of paper chromatography on Whatman filter paper coupled with ninhydrin reaction enabled RLB to make a simple conclusion. There was little evidence in favor of the presence of large pools of more than one (at most three) free amino acids until at least the fairly advanced trocophore stage of the embryos (Brahmachary and Bhattacharya, 1963), implying that most of the new protein synthesis either occurred late, or that the precursors of new protein synthesis were not free amino acids. Using the then novel technique of electrophoresis, the authors confirmed these results and concluded:

"...the free amino acid pattern is maintained (in the early embryos) by breaking down some of the proteins: This would be further evidence for the 'stubborn' gene determined biochemical pattern of individuality".

Their results implied that genes in the mother have laid down the information for a programmed series of morphogenesis to gradually unfurl in early embryos. With this publication, RLB was on a roll towards the discovery of a molecular identity of a morphogenetic field, which leads to a program of developmental phenomena in Limnaea, the temporal and spatial patterns of which he had already reported the year before (Brahmachary, R. L., 1962).

Ponder the times for a moment. Just the year before, Gunther Stent and Sydney Brenner (the former then a "Senior Postdoctoral 
Fellow" in the latter's Cambridge laboratory in Berkeley, California) tentatively wrote, "...the formation of ribosomal RNA, and hence of the quantity of protein synthesis, seems to depend on the availability of amino acids" (Stent and Brenner, 1961). Through his deceptively simple question and by his elegantly simple technique, RLBappears to strike at the heart of a fundamental question in embryology: is there sufficient raw material immediately post fertilization to make new proteins that must be the building blocks of the bewildering arrays of morphogenetic changes visible during the early cleavage stages? Or must we postulate additional mechanisms to explain early embryogenesis? This line of thought helps place RLB's earliest contributions squarely within the core of the emerging revolution in molecular embryology.

In retrospect, we can speculate that a part of RLB's results might indeed be due to a combination of stored higher molecular proteins in the yolk granules having been degraded to provide the required amino acids and the amino acid precursors for protein synthesis are "charged" by attachment to the tRNA molecules and thus might not be readily diffusible under RLB's experimental conditions to be separable by paper chromatography. The identities of the few spots of ninhydrin-positive 'free amino acids' remained unknown, as did a 'faint' but reproducible, rapidly migrating spot that did not correspond to any known amino acid. In a subsequent report, RLB identified two pools of free serine and glutamic acid, by running pure preparations of each of the twenty amino acids side by side, and confirmed that by the early hatching-stage of the snail eggs up until the late trocophore stage of post-fertilization development, the relative composition of the pools of the free amino acids does not change substantially. He concluded:

"The relatively higher intensity of some pools over others, that is constantly maintained either by using up some pools very quickly or by replenishing the more intense pools alone by lysis of older tissue or by a consistent higher rate of biosynthesis, can be regarded as a genetically fixed biochemical index" (Brahmachary, R. L., 1963).

The above conclusion again harkens back to the idea of the instructional role of genes in determining the nature of the "creative" morphogenetic field. But what is the nature of this instruction?

By 1960, the inescapable conclusion was that RNA, specifically mRNA, might be the information. The antibiotic actinomycin $D$, and its relative chromomycin, were known to inhibit the synthesis of RNA on DNA templates; so one could in principle prevent the synthesis of RNA, and then look at its phenotypic effects on the developing embryo. If RNA is pre-made and loaded into the egg in the mother, and if early embryogenesis is only dependent on this maternal instruction, then there would be little new synthesis of RNA and/or little if any phenotypic effects of the inhibition of RNA synthesis in early embryos. RLB forayed into another model of invertebrate to address this question: Ciona intestinalis or sea squirt, which is one of the closest invertebrates related to the extant vertebrates. The reasons for this initial foray are unclear to the author of this paper; one can speculate that RLB had chosen this because he was visiting Sicily at the time, hosted by Professor Giuseppe Reverberi at the University of Palermo, who had been doing insightful work on Ciona embryogenesis, and was a leading embryologist in Europe. The early experimental results were striking (Brahmachary, R.L., Reverberi, G., 1964): chromomycin had no effect on embryogenesis until the middle gastrulation stage; however, there was drastic abnormal morphological effects if the embryos were treated with chromomycin for an hour in late gas- trula or subsequent stages. This late effect was dose-dependent; treatment for only 15 minutes did not produce a detectable effect. They concluded:

"...our results... mean that the system for releasing information' is not active in the unfertilized or early fertilized egg" until late gastrulation (Brahmachary, R.L., Reverberi, G., 1964).

Conducting similar experiments with higher precision and scope, RLB published a more detailed analysis conducted in Reverberi's institute (Brahmachary, 1966), which led him to convincingly demonstrate that early cleavage was insensitive to the action of RNA synthesis inhibitors chromomycin and actinomycin D. He noted that these results are general for all invertebrate embryos, from sea urchin to Ciona, and that the early cleavage cells exhibit heterogeneous properties, some divide more rapidly than others, and some have different orientation of the spindle poles than those of others. A paradox previously demonstrated by Professor Reverberi was that a fragment of an unfertilized Ciona egg can be fertilized to produce a whole embryo, whereas a blastomere after the first cleavage of a normally fertilized egg develops into only half an embryo. Always the theorist, these observations led RLB to suggest:

"... copies of informational molecules (are) scattered throughout the unfertilized egg's cytoplasm, so that any fragment gets a whole set of information. After fertilization, new instructions are delivered to the egg or the blastomeres, namely to develop partially. These instructions are not impeded by actinomycin or chromomycin" (Brahmachary, 1966).

There was a second important finding. Based on the observation that late applications of chromomycin or actinomycin D could prevent the appearance of certain sensory organs in the developing embryos, RLB suggested that the results were in agreement with a model that proposed a "sequential release of the message" (Flickinger, 1963). Upon returning to Calcutta (now Kolkata), RLB repeated the experiments on Limnaea, and reported these results in Nature (Brahmachary and Banerjee, 1967), demonstrating the generality of the observation that the application of RNA synthesis inhibitors during the early phases of embryogenesis cannot prevent the informational field laid down within the embryos, presumably by the mother, but these do prevent the "explosive" release of the information at a later trochophore phase. This communication also hinted at a "rhythmic" or pulsatile release of the information during later embryogenesis, such that treatment with actinomycin $D$ at certain developmental stages, but not during other intermediate stages, produced defective embryos. In other words, there were repeating phases of heightened sensitivity interspersed with insensitive phases, suggesting an oscillatory rhythm in the "unmasking" of the developmental information. To RLB's mind, this immediately implied the presence of a clock-like mechanism that was predicted mathematically by Alan Turing (Turing, 1952) to arise out of the nonlinear solutions to sets of interacting diffusion equations in a morphogenetic field. He discussed this idea in the context of a review article he wrote on the possible molecular basis of biological clocks. Since we cannot match his precision and insights, we quote at some length RLB himself (Brahmachary, 1967):

"Brahmachary (1966) points out more explicitly that all the information for cleavage pattern up to gastrulation stage must exist in the unfertilized egg. He dwells on the theme that the patterns may be very different but each is genetically determined, being the same for all normal eggs of a species....Further, in embryonic 
cleavage we are concerned not merely with a spatial pattern but also with a pattern in time or rhythm. For example, in Ciona intestinalis eggs, after the first cleavage, cell division continues every 20 minutes or so till the 64-cell stage or so.... As the divisions continue normally in spite of high concentrations of actinomycin and chromomycin, it is suggested (Brahmachary, 1966) that the "instructions" must have been present as comparatively stable molecules in the cytoplasm, presumably as mRNA (assuming the hypothesis or dogma that information has its physical basis in mRNA). In other words, the information for mitosis lies in the cytoplasm. The rhythm in embryonic cell cleavage is certainly not circadian, but the fact that information for nuclear division may be located in the cytoplasm is important for our purpose...". And finally, "We have not yet succeeded in cutting the Gordian knot of "clock governing" and "clock governed" processes at the molecular level-a state of affairs that, in some ways, reminds one of the pre-Darwinian riddle-which comes first, the egg or the hen?'

It took researchers another 35 years to solve this riddle of biological clocks through the demonstration of feedback and feedforward gene regulatory circuits setting up oscillatory clocks in cell autonomous manner (Hall, 1995).

RLB adopted the techniques of incorporating radioactive precursors into RNA and protein molecules in embryos then in vogue at Jean Brachet's laboratory in Brussels (Brachet et al., 1963a, 1963b). The principle was simple: if RNA or protein synthesis occurs in a cell, then radioactive precursors of RNA or protein will be incorporated into the newly synthesized molecules. Using this rationale, RLB and his associates published a series of results between 1968 and 1972, demonstrating support for the presence of maternal mRNA in the cytoplasm of the unfertilized eggs, which are gradually transcribed to sequentially uncover the maternal instructions (Brahmachary et al., 1968; Brahmachary, R. L., Mallik, D., Tapaswi, T.K., 1971; Brahmachary, R. L., Tapaswi, P.K., Ghosal, D., 1970; Brahmachary, R.L., Ghosal, D., Tapaswi, P.K., 1971).

Starting in the mid 1970s, RLB's interest had begun to increasingly shift to ecology. RLB by that time realized that an exciting area of molecular embryology had ended and a new one had begun - one

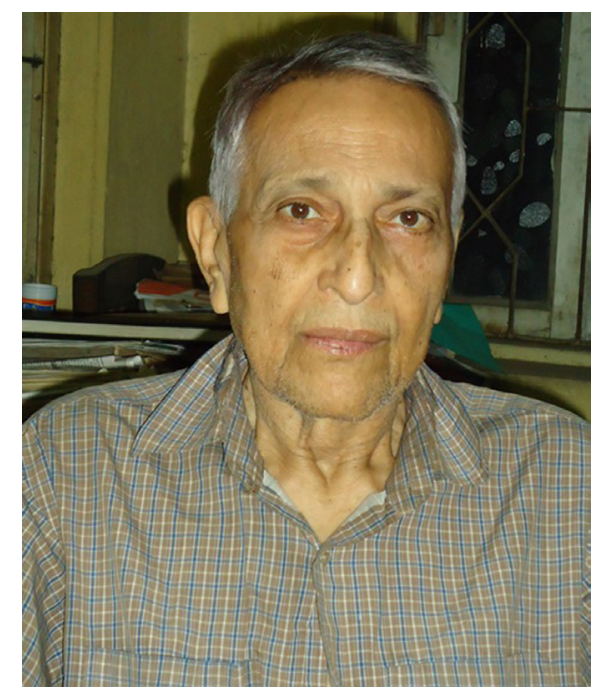

Fig. 1. Professor Ratan Lal Brahmachary in his office at the Indian Statistical Institute, Kolkata (2014). Reproduced with permission, (C) Shubhobroto Ghosh. in which he would no longer be able to compete. However, RLB was by nature a pioneer and not a system builder: he had left physics after initiating the study of relativistic field equations in the presence of static, symmetric, scalar fields (Brahmachary, 1960), which had attracted much interest later (Ureña-López, 2016), and then left embryology soon after it was clear that maternal mRNA contributes information on early patterning in the embryo.

By this time Nüsslein-Volhardt (Germany) and Wieschaus (Germany and USA) had begun to use fly genetics to identify the molecular components of maternally-derived long-lived mRNA molecules important for embryogenesis (Nüsslein-Volhard and Wieschaus, 1980; Anderson and Nüsslein-Volhard, 1984). Moving on from a conceptual phase, in which abstract models such as informational fields and morphogenetic gradients motivated most of the questions, researchers began to ask more detailed questions on the identity of the players: which genes did what, when and how. One may suppose that RLB was no longer sufficiently interested in deciphering the detailed molecular mechanisms, or perhaps he felt he was at a disadvantageous position with respect to other researchers due to the paucity of resources available to him. Meanwhile in developmental biology, profoundly important questions were raised: which maternal gene products are important for early morphogenesis, what are the gene products that allow patterns to emerge, what are the mechanisms behind the programmed unveiling of positional information through signaling within and between cells, and what are the succession of changes in gene expression at the 'receiver' end of such signaling. Formal genetics and molecular genetic techniques, which combined mechanismbased model building and testing of these through cell biological experiments, played relatively stronger roles in these discoveries than purely biochemical approaches that required breaking open the cells. Limnaea was not a suitable model system for such studies, because of its long generation time and the relative paucity of available genetic markers. Fly and worm genetics took off through the strong genetic footings established for these model systems. Sea urchin remained a favorite of several outstanding molecular biologists for the study of early events of embryo development, especially under the leadership of Eric Davidson at California Institute of Technology. This second phase of developmental biology research can be termed the stage of gene-identification, and had far-reaching practical influence. Understanding of human diseases and the development of rational therapeutics against diseases such as cancer were profoundly impacted by the advances in developmental biology in the decades since 1975.

Some words are needed here about the challenges that RLB faced during the two decades between 1960 and 1980. RLB had a two-room laboratory, one of which included his office (Fig. 1). AR saw RLB at a time when the latter used to do most of the work by himself, with some help by P. K. Tapaswi. His research funding was meager, especially during 1965-1975, which was a time of national austerity in India. Leading one of few experimental biology laboratories in the Indian Statistical Institute, he was in a difficult spot to obtain technical resources. A typical day included traveling on crowded public buses for an hour or more between his laboratory and Bose Institute in Raja Bazar, Calcutta, to use a highspeed- or ultra-centrifuge, or to read radioactive isotope incorporation by a scintillation counter. To reduce the number of such trips, I saw him in 1972 attempting to interface a Geiger-Müller counter to an oscilloscope, to innovate a less expensive, even if 
inferior, solution. He was always appreciative of the helps of colleagues at Bose Institute, who generously offered him access to their instruments. Timely access to research publications was a significant problem. It would typically take at least three months for an international journal, such as Nature, to arrive in Calcutta. Obtaining highly pure chemicals needed for analytical work was nearly impossible due to restrictive import policies of the Indian government and high prices at international markets. RLB often had to depend on gratuitous gifts by chemical companies for these essential supplies. In 1972, agarose gel electrophoresis of RNA was a relatively novel technique (Peacock and Dingman, 1968). One afternoon in 1972, AR watched RLB carefully pour molten agarose mixed with acrylamide on a glass slide, allowed the mixed gel to solidify, then push a filter paper dipped in the sample into the gel, place two wet rags bathed in buffer at the two ends and apply a voltage across the gel using a make-shift electric transformer. He would collect Limnaea at Lake "Hedo", a large pond in north Calcutta, and rear them in a glass tank. He was an avid maker of super-8mm movie films. He had rigged his microscope to record through his home-movie camera, and had taken motion pictures of snail development. AR vividly remembers RLB showing in the summer of 1974 one of his movies on the rapid rotation of developing snail embryos - most of them rotating in one direction but a small number in the opposite direction - and RLB claiming that the direction of rotation of the embryos determined the handedness of their future shells. He did not follow up on this observation, probably because soon afterwards the same correlation was published by Soviet researchers (Meshcheryakov and Beloussov, 1975). Many years later, the solution to the handedness or the left-right asymmetry problem, which was inferred by Sturtevant in 1923 to be of maternal origin contributed by a single gene, was tracked down to an asymmetric orientation of actin-induced cytoskeletal dynamics during early cleavages of the blastomeres (Kuroda, 2014).

By the early 1980s, RLB had moved on to the problem of chemical communication in animals, discovering in the process a pheromone from tiger that confers the characteristic aroma of a variety of fragrant rice (Brahmachary et al., 1990), and subsequently a number of other possible pheromones (Poddar-Sarkar and Brahmachary, 2004), which paved the way for the study of chemical communication in mammals (Sarkar and Brahmachary, R. L., 2014).

$\mathrm{RLB}$, as a 13-year old refugee fleeing violence before the impending partition of Bengal had written two letters to Albert Einstein (See Supplementary Material 1; Brahmachary, R. L., 1945), hoping to get the latter's attention. There is no record on whether RLB received a reply. However, upon the recommendation of Professor S. N. Bose (of Bose-Einstein statistics and the Boson fame), RLB went to Germany to study theoretical physics. For family-related reasons, RLB had to return to Calcutta before being formally awarded a PhD. Shortly thereafter, he was offered a position at the Indian Statistical Institute by Professor P. C. Mahalanobis, the founding director of the institute. Legend has it that when Mahalanobis asked RLB how much he would like to be paid as a salary, RLB blurted out that he had little need except to look after his mother, so a monthly salary of Rs. 30 would do. He was offered a starting salary of Rs. 100.

RLB was a dynamic personality with a spring in his gait. He was a polyglot, with considerable fluency in French, German, Italian, and Swahili, in addition to English and his mother tongue, Bengali. He had a profound knowledge of Sanskrit and a working knowledge of Russian and Spanish. Never imperious, he was always kind, and outstandingly articulate on nearly any topic except sports. He was an avid traveler and an expert in wildlife ecology. While he was able to make a young student immediately feel at ease, he was somewhat shy, never able to do small-talks, and could be diffident among colleagues. The author of this communication came to know RLB in 1971, when AR was an undergraduate student. He had accidentally found RLB's review article on information transfer in embryogenesis (Brahmachary, 1968) in the British Council Library (at the time situated on Theatre Road, Calcutta) at a period when frequent blasts of bombs meant that classes in Presidency College (now Presidency University) were often cancelled. AR subsequently sought out RLB at the Indian Statistical Institute. They formed an unequal friendship for many years, frequently discussing their mutual interests in biology, environment, the natural world, and a mad desire to travel to strange places. The last time they had extensive discussions was when AR was a student in Jawaharlal Nehru University in 1978. RLB came over and stayed at his dormitory for a few days, and together they visited the Delhi zoo to see a colony of painted storks and watched migrating ducks in a ravine near the village of Mehrauli. In 1993, AR's daughter, then ten-years old, interviewed RLB in his office (See Supplementary Material 2). AR by sheer chance came upon RLB at a pharmacy in Dum Dum, Kolkata, one winter evening in 2009 during a power cut. They had a brief but animated discussion on RLB's latest work on L-grammar, and AR's work on genomic robustness while standing in the darkness. That was the last time they met. RLB made a profound influence during AR's formative years, even though, regrettably, AR was never a direct student of RLB. AR dedicates this article to RLB's memory.

\section{Acknowledgement}

I thank Dr. Mousumi Poddar Sarkar (Department of Botany, University of Calcutta) for preparing a list of RLB's publications.

\section{References}

ANDERSON, K.V., AND NÜSSLEIN-VOLHARD, C. (1984). Information for the dorsal--ventral pattern of the Drosophila embryo is stored as maternal mRNA. Nature 311: 223-227.

BOYCOTT, A.E., AND DIVER, C. (1923). On the inheritance of sinistrality of Limnaea peregra. Proc $R$ Soc Lond B 95: 207-213.

BRACHET, J., FICQ, A., AND TENCER, R. (1963a). Amino acid incorporation into proteins of nucleate and anucleate fragments of sea urchin eggs: Effect of parthenogenetic activation. Exp. Cell Res. 32: 168-170.

BRACHET, J., DECROLY, M., FICQ, A., AND QUERTIER, J. (1963b). Ribonucleic acid metabolism in unfertilized and fertilized sea-urchin eggs. Biochim. Biophys. Acta BBA - Spec. Sect. Nucleic Acids Relat. Subj. 72: 660-662.

BRAHMACHARY (1966). Further investigations on the effects of chromomycin on morphogenesis of Ciona intestinalis. Acta Embryol. Morphol. Exp. 9: 25-30.

BRAHMACHARY, R.L. (1953a). Sur la possibilité d'un nouveau modèle statique de cosmologie. Naturwissenschaften 40: 51-51.

BRAHMACHARY, R.L. (1953b). Sur la possibilité d'un nouveau modèle statique de cosmologie. II. Naturwissenschaften 40: 313-314.

BRAHMACHARY, R.L. (1955a). On the cosmological implication of galactic magnetic fields. II Nuovo Cimento 1955-1965 1: 953-954.

BRAHMACHARY, R.L. (1955b). On the cosmological implication of galactic magnetic fields II. II Nuovo Cimento 2: 149-151.

BRAHMACHARY, R.L. (1957). A class of exact solutions of the combined gravitationa and electro-magnetic field equations of general relativity. II Nuovo Cimento 6: 
1502-1506.

BRAHMACHARY, R.L. (1960). A Solution of the Combined Gravitational and Mesic Field Equations in General Relativity. Prog. Theor. Phys. 23: 749-750.

BRAHMACHARY, R.L. (1967). Physiological Clocks. In International Review of Cytology, G.H. Bourne, and J.F. Danielli, eds. (Academic Press), pp. 65-89.

BRAHMACHARY, R.L. (1968). Information transfer in embryonic development. Prog. Biophys. Mol. Biol. 18: 107-121.

BRAHMACHARY, R.L., AND BANERJEE, K.P. (1967). Information Transfer in Molluscan Embryos. Nature 214: 172-173.

BRAHMACHARY, R.L., AND BHATTACHARYA, A. (1963). Free amino-acids in the snail Limnaea and their changes with morphogenesis. Experientia 19: 143-144.

BRAHMACHARY, R.L., BANERJEE, K.P., AND BASU, T.K. (1968). Investigations on transcription in Limnaea embryos. Exp. Cell Res. 51: 177-184.

BRAHMACHARY, R.L., SARKAR, M.P., AND DUTTA, J. (1990). The aroma of rice.. and tiger. Nature 344: 26.

BRAHMACHARY, R. L. (1945). Brahmachary, R.L., letters to Albert Einstein.

BRAHMACHARY, R. L. (1962). Progressive Localization of Neutral-Red Positive Region with Morphogenesis in Limnaea. Experientia 15: 317-312.

BRAHMACHARY, R. L. (1963). Free Amino Acids in Limnaea III. Experientia 20: 134.

BRAHMACHARY, R. L., MALLIK, D., TAPASWI, T.K. (1971). Transcription and Degradation of Heavy (pre 28 S) RNA and 4 S RNA during Embryogenesis in Limnaea. Z. Für Naturforschung Teil B 27: 1264-1266.

BRAHMACHARY, R. L., TAPASWI, P.K., GHOSAL, D. (1970). Transcription of 4S RNA in Limnaea (mollusc) Embryos. Z. Für Naturforschung Teil B25: 1318-1319.

BRAHMACHARY, R.L., GHOSAL, D., TAPASWI, P.K. (1971). Rhythmic incorporation of P32 and C14 -uracil in early mitotic cycles of Limnaea (mollusc) eggs. Z. Für Naturforschung Teil B 26: 822-824.

BRAHMACHARY, R.L., REVERBERI, G. (1964). On the action of Chromomycin on the eggs and embryos of Ciona intestinalis. Experientia 20: 621-623.

BRENNER, S., JACOB, F., AND MESELSON, M. (1961). An unstable intermediate carrying information from genes to ribosomes for protein synthesis. Nature 190: 576-581.

CRICK, F.H.C. (1963). The Recent Excitement in the Coding Problem. In Progress in Nucleic Acid Research and Molecular Biology, J.N. Davidson, and W.E. Cohn, eds. (Academic Press), pp. 163-217.

DAWID, I.B. (1965). Deoxyribonucleic acid in amphibian eggs. J. Mol. Biol. 12:581-599.

FINAMORE, F.J., AND CROUSE, G.T. (1958). Nucleotide and nucleic acid metabolism in developing amphibian embryos: I. Isolation and chemical identification of acid-soluble nucleotides. Exp. Cell Res. 14: 160-165.

FLICKINGER, R.A. (1963). Cell Differentiation: Some Aspects of the Problem. Sci- ence 141: 608-614

GILBERT, S.F. (2000). Diachronic Biology Meets Evo-Devo: C. H. Waddington's Approach to Evolutionary Developmental Biology. Integr. Comp. Biol. 40: 729-737.

HALDANE, J.B.S (1941). New Paths in Genetics (London: Allen \& Unwin).

HALL, J.C. (1995). Trippings along the trail to the molecular mechanisms of biological clocks. Trends Neurosci. 18: 230-240.

JACOB, F., AND MONOD, J. (1961). Genetic regulatory mechanisms in the synthesis of proteins. J. Mol. Biol. 3: 318-356.

KELLER, E.F. (1995). Refiguring Life: Metaphors of Twentieth-century Biology (Columbia University Press).

KURODA, R. (2014). How a Single Gene Twists a Snail. Integr. Comp. Biol.54:677-687.

LEWIS, E.B. (1963). Genes and Developmental Pathways. Am. Zool. 3: 33-56.

MESHCHERYAKOV, V.N., AND BELOUSSOV, L.V. (1975). Asymmetrical rotations of blastomeres in early cleavage of gastropoda. Wilhelm Rouxs Arch. Dev. Biol. 177: 193-203.

SARKAR, M.P., AND BRAHMACHARY, R. L. (2014). Pheromones of tiger and other big cats. In Neurobiology of Chemical Communication, C. Mucignat-Caretta, ed. (CRC Press), pp. 408-456.

NÜSSLEIN-VOLHARD, C., AND WIESCHAUS, E. (1980). Mutations affecting segment number and polarity in Drosophila. Nature 287: 795-801.

PEACOCK, A.C., AND DINGMAN, C.W. (1968). Molecular weight estimation and separation of ribonucleic acid by electrophoresis in agarose-acrylamide composite gels. Biochem 7: 668-674.

PODDAR-SARKAR, M., ANDBRAHMACHARY, R.L. (2004). Putative chemical signals of leopard. Anim. Biol. 54: 255-259.

SCHRÖDINGER, E. (1944). What is Life?: With Mind and Matter and Autobiographical Sketches (Cambridge University Press).

SPEMANN, H. (1927). Croonian Lecture:-Organizers in animal development. Proc $R$ Soc Lond $B$ 102: 177-187.

STENT, G.S., AND BRENNER, S. (1961). A Genetic Locus for the Regulation of Ribonucleic Acid Synthesis. Proc. Natl. Acad. Sci. USA 47: 2005-2014.

STURTEVANT, A.H. (1923). Inheritance of direction of coiling in Limnaea. Science 58: 269-270.

TURING, A.M. (1952). The chemical basis of morphogenesis. Phil Trans $R$ Soc Lond $B$ 237: 37-72.

UREÑA-L'OPEZ, L.A. (2016). Scalar fields in Cosmology: dark matter and inflation. J. Phys. Conf. Ser. 761: 012076.

WADDINGTON, C.H. (1940). Organizers and Genes (Cambridge University Press).

WADDINGTON, C. H. (1975). The Evolution of an Evolutionist (Ithaca, NY: Cornell University Press, Ithaca, NY). 
Further Related Reading, published previously in the Int. J. Dev. Biol.

Retinoid signalling is required for information transfer from mesoderm to neuroectoderm during gastrulation Ferran Lloret-Vilaspasa, Hans J. Jansen, Koen de Roos, Rosh A.S. Chandraratna, Maija H. Zile, Claudio D. Stern and Antony J. Durston Int. J. Dev. Biol. (2010) 54: 599-608

Retinoic acid is required for specification of the ventral eye field and for Rathke's pouch in the avian embryo

Malcolm Maden, Aida Blentic, Susan Reijntjes, Sophie Seguin, Emily Gale and Anthony Graham Int. J. Dev. Biol. (2007) 51: 191-200

The progress zone model for specifying positional information.

Lewis Wolpert

Int. J. Dev. Biol. (2002) 46: 869-870

Positional information in vertebrate limb development; an interview with Lewis Wolpert. Cheryll Tickle

Int. J. Dev. Biol. (2002) 46: 863-867

Morphological evidence for a morphogenetic field in gastropod mollusc eggs.

S E Tyler, R D Butler and S J Kimber

Int. J. Dev. Biol. (1998) 42: 79-85

Life of Alexander G. Gurwitsch and his relevant contribution to the theory of morphogenetic fields.

L V Beloussov, J M Opitz and S F Gilbert

Int. J. Dev. Biol. (1997) 41: 771-777

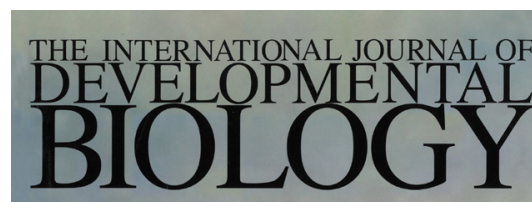

Volume 47 Nos. 7/8

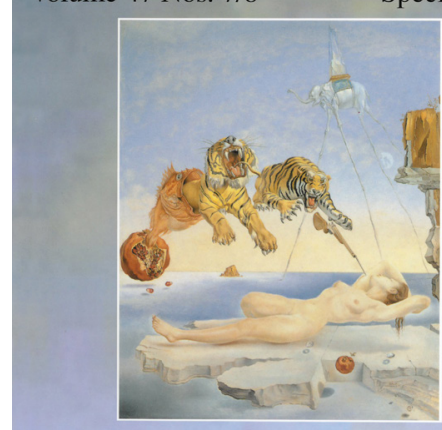

Evolution \& Development

Special Issue
5

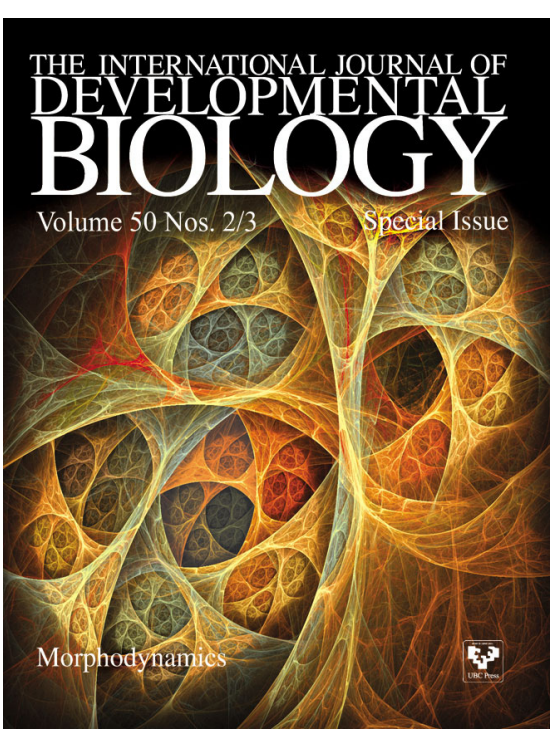

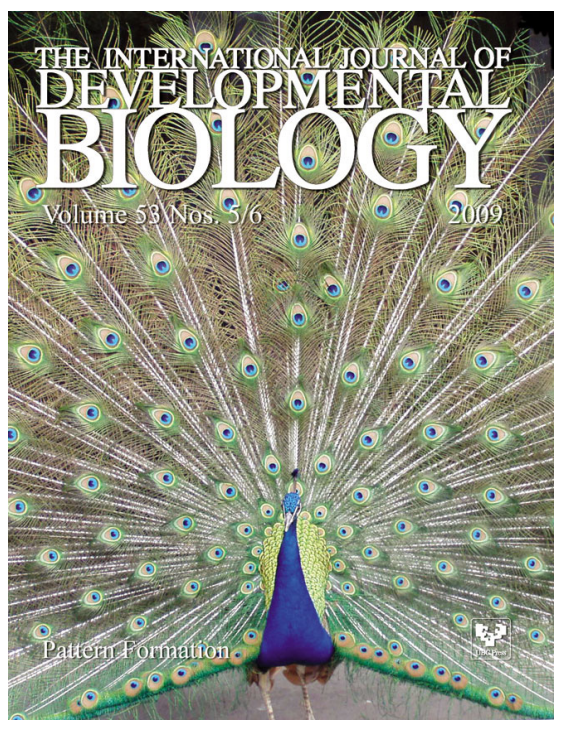

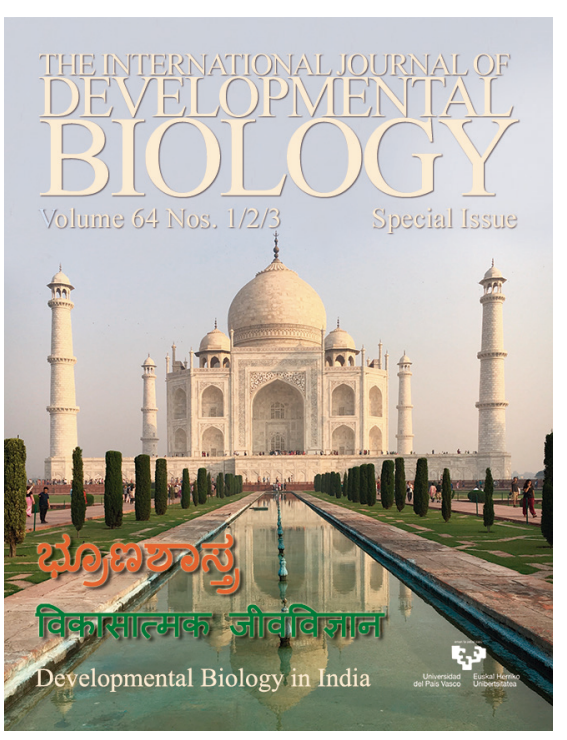

